\title{
Jaime de la Jara Figueroa \\ (Temuco, 19 de febrero, 1932 - Santiago, 9 de mayo, 2017)
}

Fue un destacado académico e intérprete en el violín. Inició sus estudios musicales en la sureña ciudad natal de Temuco, y los continuó en el entonces Conservatorio Nacional de Música perteneciente a la Facultad de Ciencias y Artes Musicales, antecesora de la actual Facultad de Artes, con maestros del calibre de Luis Mutschler y Enrique Iniesta, entre otros. Después de cursar en la Facultad los ocho años correspondientes a la Etapa Básica y los cuatro años correspondientes a la Etapa Superior, recibió en 1975 el título de Intérprete Musical de parte del Instituto de Música de la Pontificia Universidad Católica de Chile (PUC). En el intertanto, perfeccionó su formación entre 1962 y 1963 en la Musichochschule de Colonia, Alemania.

Como intérprete, su quehacer fue ampliamente interinstitucional en el terreno de la música orquestal, la música de cámara y la música solística. Se desempeñó como integrante de la Orquesta Sinfónica de Chile (1955-1971) donde llegó a ser ayudante de concertino. Fue miembro fundador de la Orquesta de Cámara del Instituto de Música de la PUC y su concertino durante quince años (19641979). Se desempeñó como concertino de la entonces Orquesta Filarmónica Municipal de Santiago (1981-1989) y de la Orquesta de Cámara de Chile (1990, 1992-1994). Su nivel sobresaliente como músico traspasó muy pronto las fronteras del país. Fue concertino de la Orquesta Filarmónica de Bogotá (a contar de 1980) y de la Orquesta Sinfónica de Baleares en Palma de Mallorca, España (1993-1994).

En paralelo, el profesor Jaime de la Jara cultivó intensamente la música de cámara. Después de integrar el Cuarteto del Conservatorio se desempeñó como primer violín de conjuntos que marcaron una honda huella en Chile y América Latina: el Cuarteto Chile (1966-1984 y 1990-1992) y el Cuarteto Latinoamericano (1978-1984). En esta calidad participó en ciclos memorables del Cuarteto Chile, como fuera la presentación de los cuartetos completos de Béla Bartók en 1977.

Como solista estrenó en Chile y en el extranjero numerosas obras del repertorio chileno, latinoamericano e internacional, con acompañamiento de piano u orquesta. En una entrevista realizada por la profesora María Soledad Morales, publicada en la recordada revista Músic@Sonido impulsada por el académico Mario Silva Solís como Director del Departamento de Música y Sonología, Jaime de la Jara señaló: "Uno tiene la obligación, como músico chileno, de dar a conocer e interpretar la música de nuestros compositores".

Esto lo materializó en un ciclo como la Retrospectiva de la música chilena para violín y piano, realizada entre 1984 y 1985, con la colaboración de figuras como René Reyes, Juta Matthei, Elvira Savi (Premio Nacional de Artes Musicales, 1998) y Cirilo Vila (Premio Nacional de Artes Musicales, 2004). Junto con esta retrospectiva realizó otros ciclos dedicados a la música centroeuropea con la colaboración del pianista Oscar Gacitúa, como la presentación de las sonatas para violín y piano de Ludwig van Beethoven en 1970 y las de Johannes Brahms en 1971.

Esta impronta interinstitucional fue también el sello de su fecunda labor como maestro del violín. Fue Profesor Titular de la Facultad de Artes de la Universidad de Chile, institución a la que ingresó en 1962. Además, fue profesor en el Instituto de Música de la PUC (1967-1978), el Instituto de Música de la Universidad de Concepción (1977-1989) y del Conservatorio de Música de la Universidad Austral en 1989. En el extranjero fue profesor visitante en Bogotá, Colombia (1980), en Centroamérica (1981), y en 1993 fue nombrado profesor del Conservatorio de Palma de Mallorca en España.

Su legado como profesor pervive en sus numerosos discípulos que, junto con proseguir carreras solísticas, integran en la actualidad conjuntos como la Orquesta Sinfónica de Chile, la Orquesta Filarmónica, la Orquesta Sinfónica de Concepción, y la Orquesta Mundial Juvenil, entre otras. Su macizo legado como músico fue reconocido por galardones como el Premio CRAV, especialidad música chilena en 1966, el Premio de la Crítica discernido por el Círculo de Periodistas en 1978 y el Premio Presidente de la República en 1999. Profundamente religioso, su legado como persona ejemplar y dedicado padre de familia pervive en sus tres hijos: Felipe, Jaime y Cristián, de su matrimonio con la amada compañera de su vida: Marta Fuentes, profesora de castellano, y como Jaime, cultora de la música como integrante del Coro Sinfónico de la Universidad de Chile.

Luis Merino Montero Departamento de Música Facultad de Artes Universidad de Chile lmerino@uchile.cl 